\title{
Regenerasi Jamuju (Dacrycarpus imbricatus (Blume.) de Laub.) di Cagar Alam Gebugan, Kabupaten Semarang Jawa Tengah
}

\author{
Jamuju's (Dacrycarpus imbricatus (Blume.) De Laub.) regeneration \\ in the Gebugan Nature Reserve, Semarang Regency, Central Java
}

\author{
Evananda Waskitaningtyas ${ }^{1}$, Sri Utami $^{2 *}$, Erry Wiryani ${ }^{3}$ \\ ${ }^{1,2,3}$ Departemen Biologi, FSM, Universitas Diponegoro \\ Jl. Prof. H. Soedarto, SH, Tembalang, Semarang 50275 Indonesia
}

\begin{abstract}
ABSTRAK
Cagar Alam Gebugan merupakan salah satu hutan lindung yang masih memiliki habitat alami Dacrycarpus imbricatus. D. imbricatus memiliki potensial penghasil kayu yang banyak digunakan oleh masyarakat, sehingga jamuju banyak dieksploitasi yang menyebabkan jenis pohon ini sulit ditemukan di habitat alaminya. Penelitian ini bertujuan untuk mengetahui regenerasi $D$. imbricatus. Penentuan plot menggunakan metode sistematik. Jumlah plot yang digunakan yaitu sebanyak 15 dengan luas masing-masing plot $10 \mathrm{~m}$ x $10 \mathrm{~m}$. Masing-masing plot dihitung jumlah individu jamuju pada tingkat pohon, tingkat tiang, tingkat pancang dan tingkat semai. Data mengenai distribusi $D$. imbricatus diolah dengan menggunakan analisis distribusi Poisson. Hasil penelitian menunjukkan bahwa regenerasi jamuju di Cagar Alam Gebugan berjalan kurang baik, hal ini ditunjukkan oleh kerapatan individu tingkat pohon 33 ind/ha, tingkat tiang (tidak ditemukan), pancang 27 ind/ha, dan semai $140 \mathrm{ind} / \mathrm{ha}$. Faktor lingkungan jamuju ditemukan tumbuh pada ketinggian $1.050 \mathrm{~m} \mathrm{dpl,} \mathrm{suhu} 26,7^{\circ} \mathrm{C}$ sampai $27^{\circ} \mathrm{C}$, kelembaban $53 \%$ sampai $61 \%$, pH tanah 6,3 sampai 7. Perlu dilakukan pengelolaan pertumbuhan pohon jamuju terutama pada fase tiang dan pancang agar populasinya pohon tersebut terjaga dari ancaman kepunahan.
\end{abstract}

Kata Kunci: Dacrycarpus imbricatus, Cagar Alam Gebugan, regenerasi, anakan pohon, semai

\begin{abstract}
Gebugan Nature Reserve is one of the protected forest that still has the natural habitat of Dacrycarpus imbricatus. D. imbricatus has the potential of producing wood that is widely used by the people while the exploitation of Jamuju causes this tree species difficult to find in their natural habitat. The aim of this research was to asses $D$. imbricatus regeneration. The method used for taking jamuju was systematic method. The number of plots used were 15 with $10 \mathrm{~m}$ x $10 \mathrm{~m}$ area for each plot. The number of individual jamuju at the tree level, pole level, sapling level and seedling level were counted at each plot. The result of this research showed the regeneration of jamuju in Gebugan Nature Reserve was poor, indicated by tree-level individual density ( 5 individuals $/ 0.15 \mathrm{ha}=33.3 \mathrm{ind} / \mathrm{ha}$ ), pole level (not found), sapling ( 4 individuals $/ 0.15$ ha $=26.6 \mathrm{ind} / \mathrm{ha}$ ), and seedlings $(21$ individuals $/ 0.15 \mathrm{ha}=140 \mathrm{ind} / \mathrm{ha}$ ). The environmental factors of Jamuju were found to grow at the altitude of $1,050 \mathrm{~m}$ asl, temperature $26.7^{\circ} \mathrm{C}$ to $27^{\circ} \mathrm{C}$, humidity $53 \%$ to $61 \%$, soil $\mathrm{pH} 6.3$ to 7 .
\end{abstract}

Keywords: Dacrycarpus imbricatus, Gebugan Nature Reserve, regeneration, sapling, seedling.

\section{Pendahuluan}

Tumbuhan jamuju (Dacrycarpus imbricatus) merupakan tumbuhan berbiji terbuka yang tumbuh liar, dan merupakan tumbuhan asli Indonesia yang bersifat endemik. Tumbuhan ini memiliki fungsi ekologis penting antara lain sebagai sumber karbon, mendukung komunitas mikroba tanah, meningkatkan nutrisi tanah, dapat mengkonservasi dan air (Rahadiantoro et al. 2013). Jamuju memiliki potensi sebagai bahan baku pembuatan mebel, papan, peralatan pertukangan maupun bahan kerajinan karena kayunya termasuk jenis kayu awet dan kuat, dengan

\footnotetext{
* Penulis korespondensi:

E-mail: utami.biologi@gmail.com
} 
serat kayu yang indah dan halus, sehingga banyak dieksploitasi oleh masyarakat. Aktivitas manusia seperti pembukaan lahan dan pengambilan jamuju di hutan alam secara berlebihan tanpa diimbangi dengan kegiatan konservasi dapat mengancam keberadaan jamuju di alam. Eksploitasi menyebabkan jamuju sulit ditemukan di habitat alaminya. Populasi jamuju di Taman Nasional Gede Pangrango menunjukan regenerasi yang kurang baik, terlihat sedikit ditemukannya permudaan pada tingkat semai dan pancang (Bramasto, 2008), dan di Bali jamuju sudah termasuk langka (Sujarwo, 2014). Menurut data IUCN (International Union for Conservation of Nature) jamuju masuk tumbuhan daftar merah dengan status Least Concern (beresiko rendah). Di Indonesia jamuju menjadi rawan dan terancam punah jika deforestasi dan penebangan liar meningkat. Sejauh ini belum ada penilaian dan evaluasi populasi jamunu (Rahadiantoro et al. 2013). Regenerasi tumbuhan merupakan informasi sangat penting dalam upaya melindungi ekosistem (Deb and Sundriyal, 2008) termasuk populasi pohon jamuju.

Cagar alam Gebugan merupakan kawasan hutan konservasi yang tumbuh berbagai flora dan fauna. Jenis tumbuhan yang terdapat di kawasan ini salah satunya adalah D. imbricatus. Gunung Ungaran sebagian besar wilayahnya telah ditanami dengan tanaman budidaya seperti kopi dan teh sehingga hutan alami menjadi semakin berkurang karena terjadinya perubahan tataguna lahan. Tujuan penelitian untuk mengetahui status regenerasi jamuju di Cagar Alam Gebugan.

\section{Metodologi}

Tempat dan waktu.

Penelitian dilakukan pada bulan September sampai November 2017. Tempat penelitian di Cagar Alam Gebugan Kabupaten Semarang. Identifikasi tumbuhan jamuju dilakukan di Laboratorium Ekologi dan Biosistematik Departemen Biologi, Fakultas Sains dan Matematika, Universitas Diponegoro.

\section{Alat dan bahan.}

Alat yang digunakan dalam penelitian ini adalah kamera, buku catatan, alat tulis, altimeter, GPS, meteran, rafia, soil $\mathrm{pH}$ tester, hygrotermometer. Bahan yang digunakan dalam penelitian meliput itumbuhan jamuju di Cagar Alam Gebugan, Kabupaten Semarang.

\section{Teknik sampling.}

Pengambilan sampel dilakukan dengan menggunakan plot garis berpetak dan penentuan letak plot dilakukan secara sistematik. Pengambilan sampel diawali dengan cara membuat transek sepanjang 500 meter di titik awal di bagian ditemukannya jamuju pertama. Dari garis transek tersebut kemudian dibuat sub plot kanan kiri dengan jarak 100 meter dan masing-masing sub plot dibuat 3 plot berukuran $10 \times 10$ meter untuk pohon, tiang, pancang dan semai dengan jarak tiap plot 10 meter (Gambar 1).

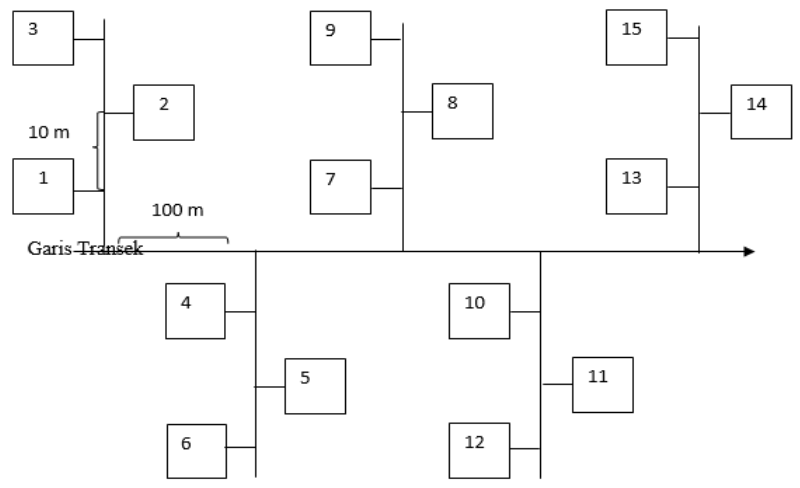

Gambar 1. Petak contoh pengambilan sampel

Pada setiap plot dilakukan pengamatan jumlah individu untuk tingkat pohon, tiang, pancang dan semai. Kriteria tumbuhan jamuju untuk tingkat pohon diamater batang $>20 \mathrm{~cm}$, tingkat tiang diameter 10-19 $\mathrm{cm}$, tingkat pancang diameter batang $<10 \mathrm{~cm}$ dan tinggi lebih dari 1,5 m serta semai tingginya kurang dari 1,5 $\mathrm{m}$ (Mandal and Joshi, 2014). 


\section{Pengukuran faktor lingkungan}

Pada setiap stasiun dilakukan pengukuran faktor lingkungan meliputi: tinggi tempat, suhu lingkungan, kelembaban serta $\mathrm{pH}$ tanah.

\section{Analisis data}

Dilakukan analisis secara deskriptif dengan perbandingan jumlah individu jamuju yang ditemukan pada tingkat pohon, tiang, pancang dan semai.

\section{Hasil dan Pembahasan}

\section{a. Perbandingan jumlah individu jamuju pada tingkat semai, pancang, tiang, danpohon.}

Berdasarkan penelitian yang telah dilakukan di Cagar Alam Gebugan, didapatkan jumlah individu jamuju untuk tingkat pohon $33 \mathrm{ind} / \mathrm{ha}$, tingkat tiang tidak ditemukan, tingkat pancang $27 \mathrm{ind} / \mathrm{ha}$ dan tingkat semai $140 \mathrm{ind} / \mathrm{ha}$. Kondisi ini menujukkan bahwa regenerasi jamuju di Cagar Alam Gebugan berjalan kurang baik. Status regenerasi yang baik jika kerapatan individu tingkat semai> tingkat pancang> tingkat tiang> tingkat pohon (Anihta et al., 2010). Menurut Deb dan Sundriyal (2008) dan Anitha et al. (2010), kemampuan regenerasi tegakan pohon dapat dilihat dari kemampuan suatu jenis pohon bereproduksi, yang dapat tercermin dari ketersediaan anakan pohon baik tingkat pancang maupun tingkat semai. Perbandingan jumlah individu pada fase semai, fase pancang, fase tiang dan fase pohon disajikan pada Gambar 2.

Gambar 2 menunjukkan adanya perbandingan jumlah individu jamuju pada tingkat semai, tiang, pancang dan pohon. Jumlah individu tingkat semai ditemukan paling tinggi dan diikuti oleh tingkat pohon, pancang, sementara itu pohon jamuju pada tingkat tiang tidak ditemukan. Perbandingan individu fase pohon, fase tiang, fase pancang dan fase semai dapat menentukan status regenerasi. Kemampuan regenerasi pohon bergantung pada keberhasilan dalam melaksanakan suatu siklus reproduksi secara utuh sejak peristiwa pembentukan kuncup bunga hingga berakhir pada perkembangan semai (Partomiharjo, 2006).

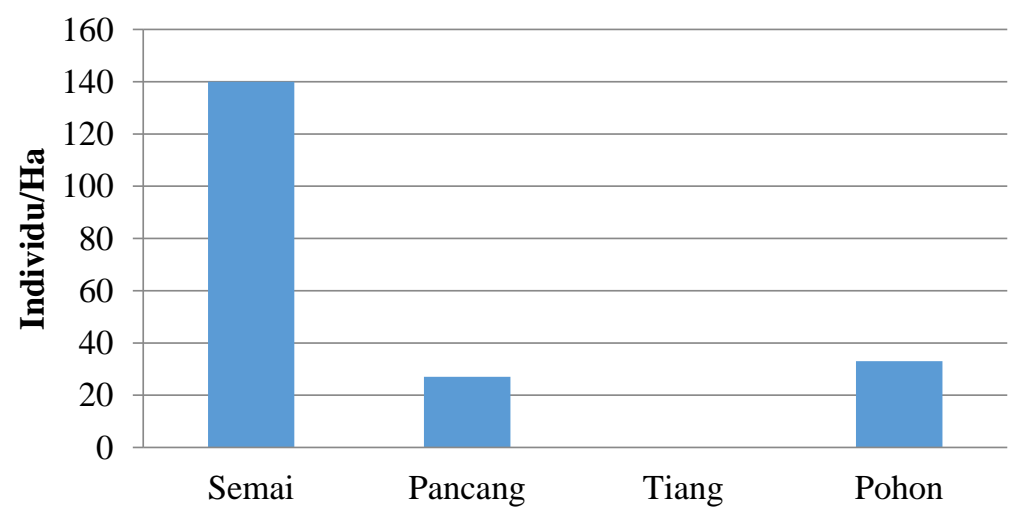

Gambar 2. Jumlah individu tumbuhan jamuju pada fase semai, pancang, tiang dan pohon.

Semai berfungsi untuk regenerasi atau menggantikan pohon yang sudah tua atau mati untuk keberlanjutan hidup pohon jamuju. Pada penelitian ini, jumlah semai jamuju yang ditemukan paling banyak sehingga dapat digunakan untuk regenerasi jamuju, tetapi pada tingkat pertumbuhan selanjutnya jumlah tingkat pancang sampai pohon semakin sedikit. Pada penelitian Utami et al (2017) juga didapatkan jumlah individu tingkat pancang dan semai paling sedikit dibandingkan jumlah individu baik tingkat semai maupun pohon. Hal ini disebabkan karena tingkat semai dan fase pancang merupakan fase pertumbuhan kritis karena semakin bertambahnya waktu, individu-individu tersebut mengalami pertumbuhan yang memerlukan banyak energi sehingga terjadi persaingan antar tumbuhan dalam mendapatkan cahaya matahari yang cukup dan unsur hara untuk pertumbuhan dan perkembangannya. Menurut Rasnovi (2006), fase semai dan fase pancang merupakan fase paling kritis dalam siklus individu suatu jenis tumbuhan karena pada tahap ini tingkat mortalitas tinggi. 
Tumbuhan jamuju pada tingkat tiang tidak ditemukan. Hal ini akan menghambat proses regenerasi pohon. Banyak faktor yang menghambat terjadinya regenerasi secara alami antara lain karena adanya berbagai tekanan yang berasal dari kegiatan manusia seperti kebakaran, kehadiran dan invasi jenis yang dominan, kehadiran dan invasi jenis eksotik, kondisi iklim mikro yang tidak sesuai, tanah yang tidak subur dan tidak adanya bank biji yang memadai.

Menurut Syamsuwida et al. (2007), jamuju memiliki pertumbuhan yang lambat. Laju pertumbuhan jamuju terbilang lambat karena selama pertumbuhan 12 bulan hanya tumbuh mencapai tinggi 0,54m (Hidayah, 2011). Pertumbuhan yang lambat kemungkinan disebabkan terjadi persaingan antara sesama jamuju dan jenis lain dalam hal unsur hara, air, ruang tumbuh dan cahaya matahari sehingga ada individu yang terkalahkan contohnya jamuju pada tingkat tiang mengalami kematian.

Jamuju mempunyai rentang tumbuh pada ketinggian tempat $900 \mathrm{~m}$ sampai $2.500 \mathrm{~m}$ dpl (Syamsuwida et al, 2007). Daerah penelitian di Cagar Alam Gebugan memiliki ketinggian tempat $1.050 \mathrm{~m}$ dpl, sehingga masih dalam rentang untuk pertumbuhannya. Penelitian (Bramasto, 2008),di Taman Nasional Gede Pangrango menunjukkan bahwa jamuju dapat ditemukan pada kisaran ketinggian 1.400- $2.045 \mathrm{~m}$ dpl.

\section{b. Kondisi lingkungan Cagar Alam Gebugan}

Sebagai data pendukung, dilakukan pengukuran faktor lingkungan yang berupa ketinggian, temperatur atau suhu udara, kelembaban udara, dan $\mathrm{pH}$ tanah. Hasil pengukuran faktor lingkungan disajkan pada Tabel 1. Berdasarkan hasil pengukuran yang dilakukan, hasil pengukuran faktor lingkungan dari plot tersebut yang telah diamati tidak terlihat perbedaan faktor lingkungan yang mencolok, karena karena jarak setiap plot berdekatan satu sama lain.Topografi ketinggian tempat ditemukannya jamuju yaitu 1.050 meter dpl.

Tabel 1. Kondisi lingkungan di Cagar Alam Gebugan Semarang

\begin{tabular}{cccccccc}
\hline \multirow{2}{*}{ No } & \multirow{2}{*}{ Parameter } & \multicolumn{7}{c}{ Plot } \\
\cline { 3 - 7 } & & 1 & 4 & 5 & 8 & 11 & 13 \\
\hline 1 & pH tanah & 6,3 & 7 & 7 & 7,1 & 7 & 7 \\
2 & Suhu udara & $27^{0} \mathrm{C}$ & $27^{0} \mathrm{C}$ & $27^{0} \mathrm{C}$ & $26,7^{0} \mathrm{C}$ & $27^{0} \mathrm{C}$ & $27,2^{0} \mathrm{C}$ \\
3 & Kelembaban udara & $61 \%$ & $61 \%$ & $61 \%$ & $53 \%$ & $60 \%$ & $61 \%$ \\
4 & Ketinggian tempat & $1.050 \mathrm{~m}$ & $1.050 \mathrm{~m}$ & $1.050 \mathrm{~m}$ & $1.050 \mathrm{~m}$ & $1.050 \mathrm{~m}$ & $1.050 \mathrm{~m}$ \\
\hline
\end{tabular}

Kondisi lingkungan tempat tumbuhnya jamuju kurang sesuai dengan iklim yang dibutuhkan jamuju. Suhu udara yang tercatat selama pengukuran faktor lingkungan berada dikisaran $26,7-27,3^{\circ} \mathrm{C}$. Kelembaban udara yang tercatat berada dikisaran 53-61\%. Jamuju dapat tumbuh secara optimum pada suhu $19-22^{\circ} \mathrm{C}$ dan kelembaban $85-99 \%$, sehingga kondisi iklim di lokasi penelitian menunjukkan kurang optimum untuk pertumbuhan jamuju, sehingga memberikan pengaruh yang kurang baik untuk pertumbuhan jamuju. Nilai $\mathrm{pH}$ tanah di lokasi penelitian dapat dikatakan netral yaitu 6,3-7,1. $\mathrm{pH}$ tanah yang dikatakan netral adalah $\mathrm{pH}$ tanah dengan nilai 6-7, dimana $\mathrm{pH}$ ini paling optimal untuk pertumbuhan dan perkembangan tanaman jamuju.

Pengelolaan terhadap pertumbuhan pohon jamuju sangat diperlukan terutama pada fase kritis yaitu pada tingkat tiang dan pancang agar terhindar dari ancaman kepunahan. Keberhasilan regenerasi merupakan faktor penting untuk kelestarian produktifitas hutan, keanekaragaman hayati dan jasa ekosistem

\section{Kesimpulan}

Pohon jamuju (D. imbricatus) memiliki regenerasi yang kurang baik, hal ini ditunjukan oleh kerapatan individu tingkat pohon $33 \mathrm{ind} / \mathrm{ha}$, tingkat tiang (tidak ditemukan), tingkat pancang $27 \mathrm{ind} / \mathrm{ha}$, dan semai $140 \mathrm{ind} / \mathrm{ha}$. Perlu pengelolaan yang baik terhadap pertumbuhan pohon jamuju terutama pada fase tiang dan pancang agar populasi jamuju tetap terjaga dan terhindar dari ancaman kepunahan. 


\section{Daftar pustaka}

Anitha K., Joseph S., Chandran R.J., Ramasamy E.V., Prasad N. 2010. Tree Species Diversity and Community Composition in Human-Dominated Tropical Forest of Western Ghats Biodiversity Hotspot, India. Ecol. Complex., 7: 217-224.

Bramasto, R. G. A. 2008. Penyebaran, Regenerasi, dan Karakteristik Habitat Jamuju(Dacrycarpus imbricatus Blume) di Taman Nasional Gede Pangarango. Skripsi. Departemen Silvikultur, Fakultas Kehutanan, Institut PertanianBogor.

Deb P., Sundriyal R.C. 2008. Tree Regeneration and Seedling Survival Pattern in Old-Growth Lowland Tropical Rainforest in Namdapha National Park, North-East India. Forest Ecol and Manag., 255: 3995-4006

Hidayah, N. 2011. Daya Sintas dan Laju Pertumbuhan Rasamala (Altingia excelsa Noronha), Puspa (Schima wallichii (DC.) Korth.), dan Jamuju (Dacrycarpus imbricatus (Blume) de Laub.) Pada Lahan Terdegradasi di Hulu Das Cisadane. Disertasi. Sekolah Pasca Sarjana Institut Pertanian Bogor. Bogor.

Mandal, G. and Joshi, S.P. 2014. Analysis of vegetation dynamics and phytodiversity from three dry deciduous foreat of Donn Valley, Western Himalaya, India, J of Asia-Pasific Biodiv., 7(3), 2014, pp. 292-304.

Partomihardjo, T. 2006. Populasi Ramin (Gonystylus bancanus (Miq.)Kurz) di Hutan Alam: Regenerasi, Pertumbuhan dan Produksi. Workshop Nasional. Bogor.

Rahadiantoro, A., Hakim, L. and Aruningtyas, E.L. 2013. Genetic Variation of Dacrycarpus imbricatus in Bromo Tengger Semeru National Park (BTS-NP), East Java. The J. of Trop. Li. Sci. 3 (2) : 127-131

Rasnovi, S. 2006. Ekologi Regenerasi Tumbuhan Berkayu pada Sistem Agroforest Karet. Disertasi. Sekolah Pasca Sarjana Institut Pertanian Bogor. Bogor.

Sillanpa, M., Vantellingen, J and Fries, D.A. 2017. Vegetation Regeneration in a Sustainably Harvested Mangrove Forest in West Papua, Indonesia. Forest Ecology and Management 390 : 137-146

Sujarwo, W. 2014. Klasifikasi kelimpahan tumbuhan di Kecamatan Kintamani Bali: Studi kasus usaha konservasi. J. Man dan Ling., 20: 276-283.

Syamsuwida D, Nurhasybi, Bramasto Y, Danu, dan Abidin A..Z. 2007. Kajian Komprehensif Benih Tanaman Hutan (Jenis-jenis Konifer). DepHut. BPTP. BOGOR

Utami S., Anggoro S., Soeprobowati T. R 2017. The Diversity and Regeneration of Mangrove Panjang Island Jepara Central Java. Int. J. Conserv. Sci., 8 (2) : 289-294 